Amazonía Peruana, Volumen XVI, No 32, 2019; p.p 133-151

\title{
LA MILITARIZACIÓN DE LOS ORIENTES PERUANOS Y ECUATORIANOS
}

\author{
(1933-194I)
}

\section{François Bignon}

\section{Resumen}

Debido al conflicto colombo-peruano de 1932, peruanos y ecuatorianos volvieron a considerar la frontera amazónica como un asunto geopolítico de primera importancia. Los dos países incrementaron sus recursos militares y llevaron a cabo una reorganización de sus fuerzas. El Perú lo consiguió de manera más exitosa que su vecino, pero esta militarización desencadenó numerosos incidentes fronterizos que fortalecían la tensión diplomática y amenazaron desatar una guerra entre las dos Repúblicas. Si la chispa de la guerra de 1941 se prendió en la región costeña y no en la Amazonía, la militarización de los Orientes que la adelantó convirtió las fuerzas armadas en la principal institución colonizadora de la década y contribuyó a redefinir la sociedad amazónica alrededor de los núcleos de guarniciones, anunciando nuevos cambios y la integración a los Estados nacionales de la segunda mitad del siglo XX.

\section{Summary}

Because of the conflict between Colombia and Peru in 1932, Peruvians and Ecuadorians began to consider the Amazon border as a geopolitical issue of utmost importance. The two countries increased their armament and carried out a reorganization of their armed forces. Peru was more successful than its neighbor, but this militarization triggered numerous border incidents which increased diplomatic tension and threatened to trigger a war between the two republics. If the war of 1941 began in the coastal region and not in the Amazon, the militarization of the eastern regions where it continued, made the armed forces into the main colonizing institution of the decade and helped redefine Amazonian society around nuclei of garrisons, announcing new changes and the integration of the nation states in the second half of the 20th century.

Palabras claves: Frontera-Perú-Ecuador-Fuerzas Armadas-guerra de 1941 
Desde el primer viaje de los europeos al río Amazonas en el siglo XVI, los asuntos militares han tenido una importancia de primer plano para conquistar, colonizar y defender la soberanía de estas regiones fronterizas. Con la época republicana, los nuevos Estados se enfrentaron para reivindicar su legado, lo que originó pleitos seculares. Entre las Repúblicas de Perú y Ecuador, este diferendo tenía como objeto, además de pequeños territorios costeños, los territorios ubicados alrededor de los afluentes septentrionales del río Marañón y del Amazonas, desde el río Chinchipe hasta el río Putumayo. Para Lima, esta región era el Nororiente peruano, mientras que, para Quito, se trataba del Suroriente ecuatoriano.

No era la primera vez que la tensión bélica internacional brotaba en esta región. En el siglo XIX, el Perú de Ramón Castilla había llegado hasta Guayaquil para impedir la venta de parte del territorio amazónico reclamado por los dos países. En la primera mitad del siglo XX, fue en la misma selva que continuó esta pelea, las tropas peruanas y ecuatorianas se habían enfrentado por el río Napo en 1903 y 1904 en los combates de Angoteros y Torres Causana y peruanos y colombianos se habían encontrado en el combate de la Pedrera en 1911 (Villar Gálvez 1999). La geografía militar de la región ya cargaba el peso de estas batallas con los nombres de los caídos para denominar las guarniciones (Cabo Pantoja, Torres Causana, Chávez Valdivia, etc.). Sin embargo, a raíz del conflicto peruano-colombiano en 1932-1933, los territorios fronterizos discutidos entre Perú y Ecuador volvieron a cobrar importancia en la geopolítica regional. Los dos países libraron una carrera de ocupación militar del territorio hasta la guerra de 1941-1942 ganada por el Perú, terminando así un ciclo de una década y empezando otro.

Apoyado en la lectura de archivos militares y diplomáticos en Perú y en Ecuador, este trabajo pretende demostrar la realidad, extensión y consecuencias de esta militarización negada a menudo en los trabajos peruanos y exagerada en los estudios ecuatorianos.

Nos preguntaremos para este fin cuáles fueron las diferencias entre las estrategias peruanas y ecuatorianas y porque Perú fue más exitoso en este proceso. Esto implica explicar la vida cotidiana de las guarniciones de frontera y la dinámica de los múltiples incidentes de frontera entre estas naciones, para enfatizar la especificidad de esta fase de proyección de los Estados sobre la Amazonía, quienes, además de otras herramientas institucionales (religiosas o civiles) apuestan por las Fuerzas Armadas para integrar estos inmensos espacios a los territorios nacionales.

\section{La herencia de Leticia en Perú}

En octubre de 1932, un grupo de peruanos procedentes de Iquitos tomaron el puerto colombiano de Leticia, para protestar por su entrega durante el gobierno de Augusto B. Leguía. El Perú entró así, sin querer, en una batalla militar y diplomática que terminó dos años después en un fracaso para Lima (Camacho 2016). En el Perú, las estrepitosas consecuencias de estos acontecimientos fueron relevantes. La 
experiencia de la guerra en terreno selvático inspiró a numerosos oficiales sobre la necesidad de crear una doctrina específica de acción militar en este entorno particular, interesándose en todos los aspectos: vías de comunicación, medidas de sanidad, táctica, vestimenta y cartografía. Estos temas fueron objeto de numerosas publicaciones en la Revista Militar del Perú y la Revista de Marina y Aviación, y en libros sobre el Ejército (Torres 1935) y la Marina (Romero 1935) por lo que sería innecesario citarlas todas. Muchas veces los autores concordaban en que las Fuerzas Armadas podían y debían ser el núcleo de la colonización del Oriente, con guarniciones del ejército protegidas por las fuerzas navales.

«Urge implantar la Colonización Militar de Loreto, en las zonas fronterizas que pretendan disputarnos algún vecino. Esta cuestión es vital e impostergable, no solo para la afirmación de la soberanía nacional, sino también para facilitar la solución del problema actual de desocupación que cada día se acentúa más en la capital del departamento (Iquitos)» (Paredes 1934)

Este comentario demuestra además que la selva era considerada, por militares y civiles, como una frontera turneriana capaz de resolver los problemas sociales internos (Walker 1987).

No todos los objetivos de estos autores se cumplieron, pero el incremento de la presencia militar fue notable. Cuando estalló el conflicto de Leticia en 1932, las tropas del Nororiente alcanzaban apenas 350 hombres y eran «sin equipo, mal vestidas y casi descalzas»; faltaba gasolina y sobre todo, sueldo ${ }^{1}$. Nueve años después, la tropa había sido multiplicada por casi cuatro, alcanzando 1246 efectivos en abril de 1941, antes de que estallara la guerra. A estas fuerzas del ejército hay que agregar las fuerzas navales que sumaban 4 cañoneras, 2 lanchas artilladas y 5 aviones que fueron, menos algunas, exitosamente usadas durante la guerra de $1941^{2}$ (Del Mar Alcázar 1980; Rodríguez Asti 2008) El material peruano había sido renovado, en parte gracias a las compras durante el conflicto con Colombia (Camacho 2016: 487-489) y muchas guarniciones habían sido avanzadas e incluso una quincena fueron creadas entre 1935 y 1941 (Zanabria Zamudio 1969: 164-195) Se nota así un verdadero esfuerzo en este ámbito.

Los estudios históricos ecuatorianos han considerado este hecho (y una situación similar en la región costeña) para denunciar un plan premeditado del Perú de invadir Ecuador (Macías Núñez 2012: 43-44) Si bien los hechos de Leticia habían empujado a las Fuerzas Armadas a considerar con más detenimiento el caso de las guarniciones de la selva y que el presupuesto de Defensa tuvo una curva ascendiente

1 "Conclusiones del Consejo de Investigación sobre Operaciones militares en el Nororiente 1932", 22 de mayo de 1936, Archivo del Centro de Estudios Histórico-Militares del Perú.

2 Antonio Santisteban, "Informe sobre la actuación de la Va. División durante la campaña librada contra el Ecuador en 1941", 30 de noviembre de 1941, Archivo del Centro de Estudios HistóricoMilitares del Perú. 
durante la década de 1930 (Calderón \& Mendoza 2016: 159) parece que el objetivo de la reforma global de las Fuerzas Armadas en estos años tenía, prioritariamente, objetivos de política interna. El general Benavides (1933-1939) y, luego, el gobierno de Manuel Prado (1939-1945) quisieron de este modo apaciguar a los militares en estos tiempos, social y políticamente, tumultuosos para el país. La División de la Selva recibió apoyo, al igual que el resto de las divisiones (Masterson 2001).

\section{Los intentos ecuatorianos}

En Ecuador, los eventos de Leticia levantaron intereses, aunque no de forma tan clara. Al parecer no hubo, como en Perú, un interés doctrinario militar hacia la selva, y los planes de guerra apuntaban más bien a conflictos en las áreas serranas (Macías Núñez 2012: 33-37). Además, es un hecho que cuando las tropas del Napo se sintieron superadas por el incremento de tropas peruanas a raíz del conflicto con Colombia, el poder político no cumplió sus promesas de incremento presupuestario, quizás para no desatar una guerra que habría sido fatal para el país en ese momento (Macías Núñez 2007: 217-220).

No obstante, una serie de medidas administrativas demuestran que el interés por asegurar las fronteras con las Fuerzas Armadas existía también en Quito. Desde 1926, estas fuerzas en el Oriente estaban organizadas en un Distrito Militar Oriente, diferente de otras zonas militares del país, que agrupaba los efectivos presentes en las provincias Napo-Pastaza y Santiago-Zamora, directamente debajo de las órdenes del ministerio de Guerra y Marina (Macías Núñez 2007: 172). La gestión militar consideraba la región como un caso que requería cuidados particulares, pero el asunto se aceleró después de la toma de Leticia en 1932. En Enero de 1933, por primera vez eran organizados dos destacamentos en el Oriente ecuatoriano, que debían juntar fuerzas del Ejército y de la Marina, y que se acompañaban de un incentivo de 50\% de sueldo adicional a los efectivos. En 1936, la Dirección de Oriente, organismo del gobierno encargado de la administración de los territorios amazónicos, encabezada tradicionalmente por un civil, se transformó en el Cuarto Departamento del Ministerio de Defensa Nacional bajo la dirección de un Comandante, confirmando así una "administración netamente militar en esta región"3. Por fin en 1940, se convierte a los batallones "Ecuador" y "Oriente" creados en 1937 para organizar las fuerzas militares ecuatorianas amazónicas, en destacamentos, a los que se agregaron un tercer destacamento "Patria" (Lloret Orellana 2013: 210, 228, 232), lo que permitió incrementar los efectivos ecuatorianos en esta parte del país de aproximadamente 420 soldados y oficiales en $1938^{4}$ a unos 700 en víspera de la guerra de 1941 (Macías Núñez 2012: 127-129), aunque el material ecuatoriano era, según múltiples

3

4
Manuel Rosales, «Del Río Napo», El Día, 19 de septiembre de 1936.

"Informe Reservado presentado por el Ministro de Defensa Nacional, Coronel Guillermo Freile, al Gobierno y Junta Consultativa, haciendo historia de las incursiones peruanas en el Oriente 
testimonios, de mala calidad, y las Fuerzas Armadas carecían de lanchas a motor o de aviones.

Además de la actividad de reorganización administrativa, hay numerosas pruebas de que las guarniciones ecuatorianas intentaban, como los peruanos, adelantar sus posiciones lo máximo que podían, aprovechándose de la definición borrosa del límite internacional. En 1935, el Director del Oriente reclamaba la creación de numerosas guarniciones de frontera para defender la soberanía y proteger las riquezas potenciales de la región, y desarrollar núcleos de población alrededor, y alentaba el nombramiento de varias comisiones de exploración. Advertía sin embargo que "la localización de las guarniciones es un problema muy delicado, porque si se sitúan demasiado cerca de la Cordillera incitan, antes que defienden la invasión peruana, como ya ha sucedido varias veces, y si avanzan demasiado pueden provocar reclamos y complicaciones internacionales" . Uno de los ejemplos paradigmáticos de estas dificultades fue la expedición para establecer una colonia agro-militar en la boca del Santiago en el Marañón en 1936. En abril de este año salió de Quito, a cargo del civil José Washington Palacios con órdenes del Director de Oriente y del Estado Mayor General, una expedición de 22 hombres y 140 bultos para «situar la Tenencia Política de Yaupi cerca de la desembocadura del río Santiago en el Marañón, a más de quinientos kilómetros del lugar en que se encontraba establecida». Llegada más de dos meses después en el Yaupi, cuyo puesto "no [era] mejor que cualquier rancho de jíbaro", y habiendo perdido una parte importante del material por los cargadores que huyeron, siguieron el camino con tres intérpretes, un soldado de Yaupi que hablaba jíbaro y conocía sus costumbres, un jíbaro educado por los salesianos y un indígena evangelizado del Napo. Llegaron una semana después a su destino en la desembocadura del Santiago, en el Marañón. Los jíbaros presentes les prestaron sus casas en la espera de construir nuevas. José Washington afirma haber llegado el 5 de julio. Al día siguiente en Lima fue firmado el Statu Quo por el cual los dos países se comprometían a no avanzar más. Las comunicaciones imposibles en esta región con Quito, José Washington aprendería la existencia del Acta de Lima semanas después, pero solo diez días después de instalarse en el Santiago llegó un contingente del ejército peruano, llevado en buques de la Marina, que capturó a los ecuatorianos, argumentando que estaban violando el Statu Quo. Debido a las corrientes, los presos fueron llevados en los buques (que impresionaron mucho al jefe ecuatoriano) hasta Cabo Pantoja en el Napo, a más de mil kilómetros de distancia, para ser devueltos a la guarnición ecuatoriana de Rocafuerte. Ninguna autoridad ecuatoriana reconoció oficialmente al jefe ecuatoriano cuya misión era secreta, y con muchas dificultades logró ya en Quito ser pagado gracias a la intervención del Presidente de la República ${ }^{6}$.

Ecuatoriano desde el año 1935", 3 de marzo de 1938, Archivo histórico del Ministerio de Relaciones Exteriores, Quito, T.5.3.1.4.

5 E.Vásconez C., "Informe del Director de Oriente acerca de la región oriental”, 19 de diciembre de 1935, Archivo Histórico del Ministerio de Relaciones Exteriores, Quito, T.5.1.20.

6 "Informe reservado que el señor J.Washington Palacios F., delegado de la dirección general de Oriente, presenta al señor encargado del mando supremo de la república [Federico Páez], acerca 
Las noticias de la expedición habían llegado a las cancillerías y Lima protestaba contra lo que consideraba una violación al reciente acuerdo. Hasta en Ginebra, Francisco Tudela, representante peruano en la Liga de Naciones, remitió un informe sobre los eventos al Secretario General de dicha institución ${ }^{7}$. Las autoridades ecuatorianas, y en primer lugar el Presidente de la República Federico Páez, se les hacía fácil subrayar que los miembros de la expedición no eran militares, y que por lo tanto no se podía considerar como incursión armada. Y cargaba el peso sobre "la Dirección de Oriente [que] había estado en completa desorganización bajo la jefatura del doctor Vásconez y que por eso el gobierno se había visto obligado a destituirlo, reemplazándole por un militar". Agregaron que "el anterior Director, mucho antes de la firma del Acta, destacó cerca de ochenta colonos por diferentes lugares y que el plan era tan descabellado y sin control, que ni siquiera tenían noticias del lugar aproximado donde podrían encontrarse" ${ }^{\prime \prime}$.

Se nota en la expedición al Santiago que los esfuerzos ecuatorianos, por ser verdaderos, sufrieron falta de coherencia y unidad política, así como las comunicaciones pésimas y la asimetría de material con los peruanos, quienes pudieron instalar su propio puesto en la zona. Este desequilibrio aparece en el asunto primordial para los militares de las poblaciones nativas.

\section{Un nuevo trato hacia los indígenas}

Las relaciones de las guarniciones con las poblaciones originarias vienen demostrando una diferencia en la implementación de la militarización oriental. Tanto peruanos como ecuatorianos tenían conciencia de la necesidad de trabajar con los indígenas, en particular en la zona jíbara, en cuanto al manejo de la información, pero también para alimentarse y practicar viajes de reconocimientos. Era además una cuestión de seguridad: en 1913, una guarnición entera de peruanos en el río Morona había sido masacrada por los jíbaros debido a las malas relaciones, lo que había retrasado dos décadas la presencia militar en la región (Guallart 1990: 197199). El comandante de la guarnición peruana de Carbajal resumió así después de la guerra la posición de las dos naciones, que se podría resumir en "atraer o alejarlos":

“Oblígame aumentar un punto a este informe a fin de tratar en él de la cuestión, que constituyen los indios de nuestra selva:

Este elemento juega un rol bastante importante en el medio que operamos, ya que se ha visto y con bastante regularidad que éstos se convienen con el bando que los

de la ocupación efectuada de la altura del "Potoshe", en el río Santiago, a una hora, en el Marañón, o sea del Pongo de Mansererrich", 4 de noviembre de 1936, Archivo Histórico del Ministerio de Relaciones Exteriores, Quito, T.5.3.1.2.

7 Francisco Tudela al Ministro de Relaciones Exteriores, “Incidente en el río Napo", 20 de julio de 1936, Archivo Histórico de Límites, Lima, LEI-6-12, legajo 569.

8 Javier Delgado al Ministro de Relaciones Exteriores, 7 agosto de 1936, Archivo Histórico de Limites, Lima, LEI-6-17, legajo 569. 
trata mejor o les parece así, cuando no es por temor y estos elementos muchas veces sirven a un bando y al otro también, dando como resultado que muchos movimientos que unos creen se realizarían con el secreto de que deben estar rodeados, habían sido descubiertos por estos indios que con el extraordinario dominio de la selva, atraviesan extensas regiones llevando las noticias a zonas donde menos se supone.

Convendría realizar un labor tendiente a alejarlos de las zonas de las guarniciones o atraérselos a la causa, mediante una hábil dirección de trabajo y culturización, a fin de que, en caso como el actual, pueda controlárseles e impedir hasta donde sea posible sus movimientos"

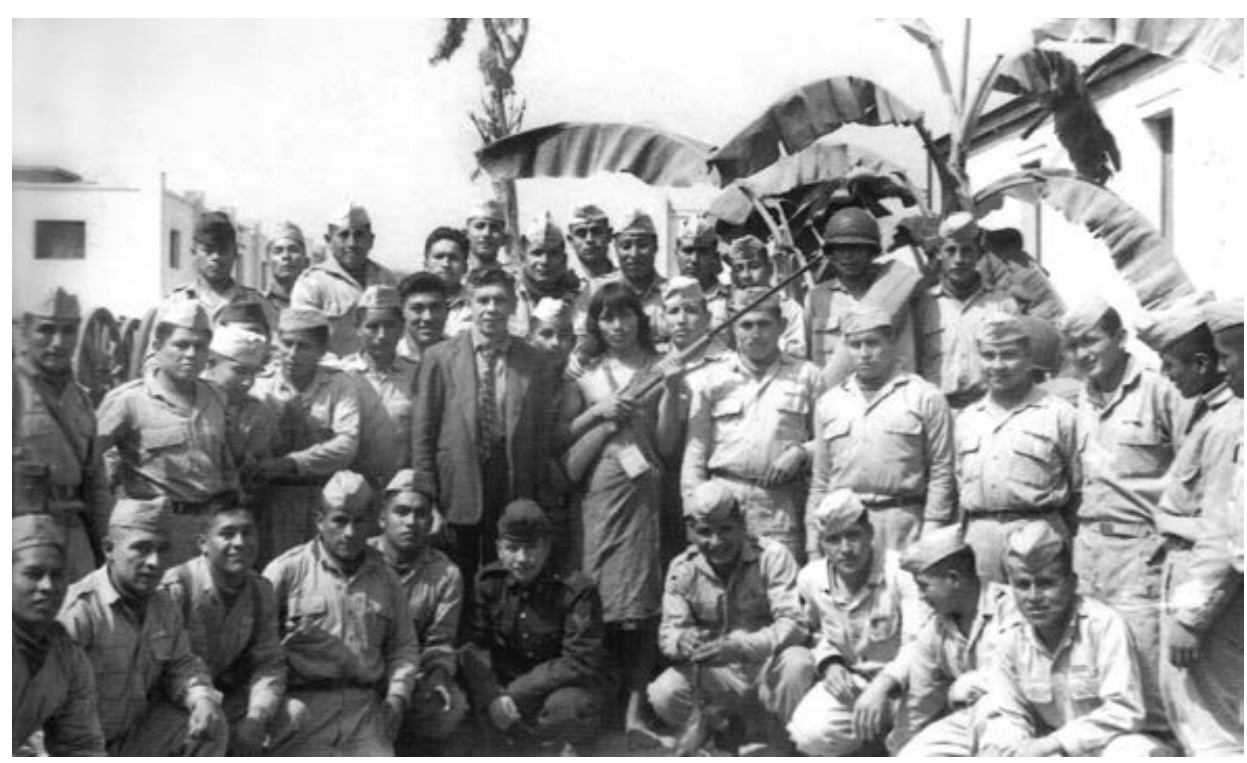

Tropas y awajún con escopeta Fotógrafo anónimo ca. 1940

Colección Micromuseo (....al fondo hay sitio)

En realidad, este trabajo de "atraérselos" había empezado años atrás, aunque no de forma sistemática, como lo atestiguan múltiples informes en los archivos, así como los mapas de guarniciones que muestran la presencia al lado de los militares de chozas de indígenas, dedicados a alimentar la guarnición con yuca y otros alimentos, y a guiar en las expediciones. Cabe destacar que este apoyo de los nativos a las guarniciones muchas veces se hacía a través de una previa evangelización o de un lazo con un antiguo cauchero, tanto para los peruanos como para los ecuatorianos, como se notó en

9 Antonio Santisteban, "Informe sobre la actuación de la V División durante la campaña librada contra el Ecuador en 1941", 30 de noviembre de 1941, Archivo del Centro de Estudios HistóricoMilitares del Perú 
el caso de la expedición al Santiago de 1936. De hecho del lado ecuatoriano, las mismas necesidades existían, y el Ministerio anunció en 1938 la decisión de crear "cuarenta vacantes en cada una de las Unidades que guarnecen las Provincias Orientales, seguro que, en esta forma, se logrará atraer a nuestros jíbaros del Oriente a la culturización y al reconocimiento de sus deberes como ciudadanos ecuatorianos" ${ }^{\prime 10}$. No se sabe si esta promesa fue cumplida, pero es más probable que no. El Mayor ecuatoriano Muñoz lo explicó con amargura después de la guerra de 1941:

"Dado el gran tiempo que el Perú ha tomado posesión de nuestro Oriente, ha logrado atraer a la mayoría de los jíbaros, siendo éstos muy obsequiados por aquellos de todos los implementos más necesarios (carabinas, cartuchos, escopetas, cuchillos, telas, veneno, etc.), logrando de esa forma atraerles para aprovecharles en el servicio de espionaje; nosotros, no hemos hecho nada al respecto"11.

Entre los dos países había empezado además una competencia para denunciar los abusos de las guarniciones enemigas hacia los indígenas a veces considerados como "connacionales" o "compatriotas". Convenía en efecto proteger ciudadanos para demostrar la presencia efectiva del Estado en tierras remotas. Pero estos dos países, una vez más, no jugaban con armas iguales, como lo comprobó otro Mayor ecuatoriano después de la guerra, considerando que los indígenas nunca podrían ser considerados verdaderos ecuatorianos:

"Cuando llegan a Méndez [guarnición y pueblo ecuatoriano] esperan que les regalen y les obsequien todo lo que quieren, si no dicen "No valiendo gobierno Ecuador, nada dando, peruano valiendo, escopeta, munición, fulminantes y taraches dando, vos no valiendo". El afán de atraerlos es imposible, pues nunca podremos dar a los jíbaros, lo que el Perú les obsequia, por eso siempre nos delatará cuando puedan y serán nuestros enemigos"12.

Aunque la acusación ecuatoriana de que los peruanos supieron atraer a los indígenas selváticos resultaba en parte retórica para justificar la catástrofe de 1941, parece cierto que los peruanos lo lograron mejor que sus vecinos, dado que durante la guerra, se notaron más indígenas del bando de Perú que de Ecuador, inaugurando una política de "fronteras vivas", que Brasil ya había usado y que

10 “Informe Reservado del Ministerio de Defensa Nacional General Guillermo Freile a la Asamblea Nacional, dando cuenta de los efectivos militares ecuatorianos, de la nueva organización del Ejército, del material para la defensa territorial y de lo que se debe hacer para mantener el Oriente Ecuatoriano", Setiembre de 1938, Archivo Histórico del Ministerio de Relaciones Exteriores, Quito, T.5.3.1.4.

11 "Mayor F.C. Muñoz Zamora, Comandante de $2^{\mathrm{a}}$ comandancia del Batallón Oriental n¹7 "Patria" a Sr. General Dn. Juan Fco. Orellana", 3 de enero de 1942, Archivo Histórico-Militar, Escuela Superior Militar "Eloy Alfaro", Quito. Bustamante, Segundo Comandante", 28 de Enero de 1942, Archivo Histórico-Militar, Escuela Superior Militar "Eloy Alfaro", Quito. 
en Perú se desarrollaría aún más en la segunda mitad del siglo (Zárate Botía 2012; Guallart 1981). Este logro se añadía a una mayor presencia numérica y a un mejor material del lado peruano, que nos obliga a enfatizar a una militarización oriental compartida entre los dos países, pero asimétrica a favor de los peruanos. A pesar de este desequilibrio, las guarniciones de los dos países se enfrentaban a similares problemas cotidianos.

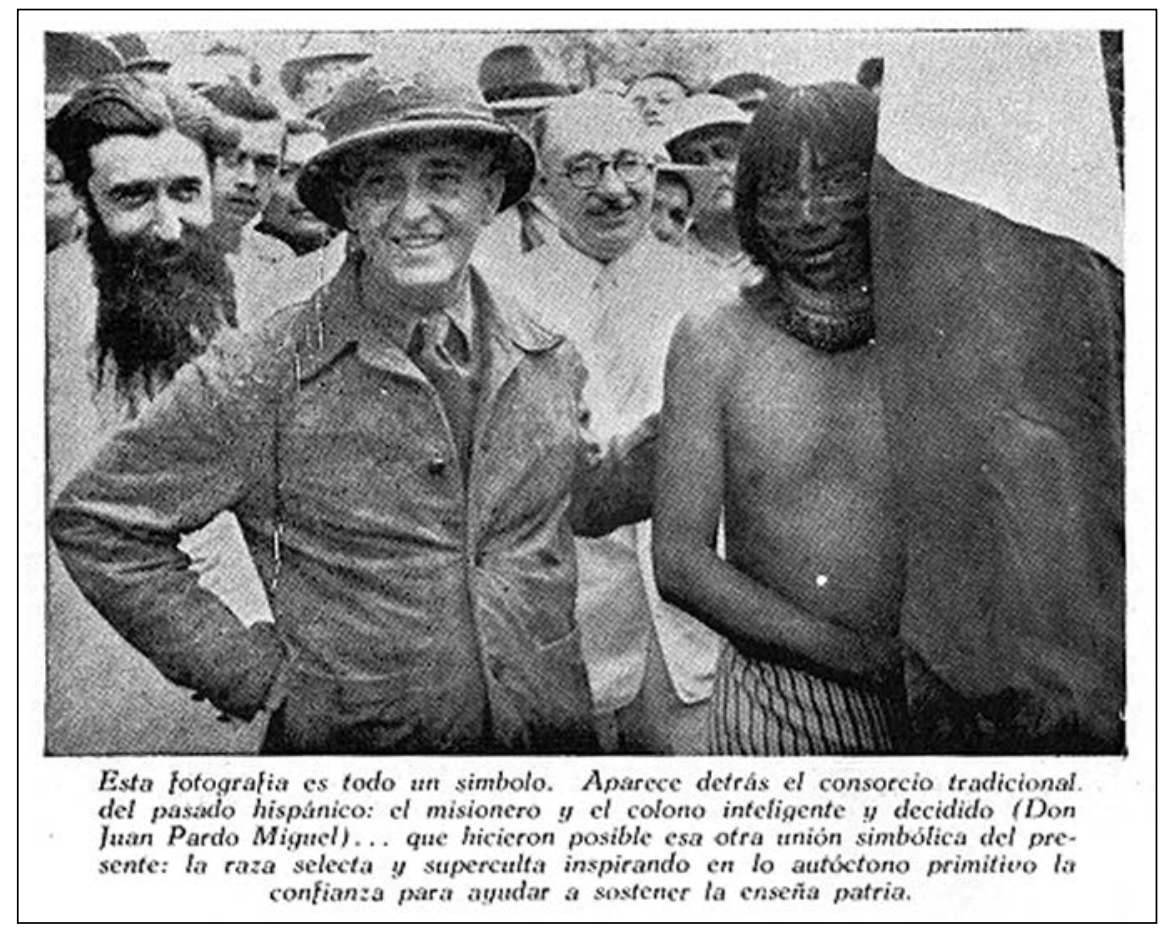

Fuente: Luz sobre el Marañón. Gonzalo Palacios de Borao, SJ. 1945. p. 54. Lima: Compañia de Jesús.

\section{Retos cotidianos de los soldados de frontera}

El total de los miembros de las Fuerzas Armadas de los dos lados sumaba entonces menos de 2000 personas, distribuidos en decenas de pequeños puestos de avanzada (compuestos de varias decenas de efectivos para los más grandes a menos de 10 en muchos casos). Estos puestos vivían en un gran aislamiento, aunque varíaba dependiendo del país y de la guarnición. Las guarniciones peruanas, a pesar de ser divididas en tres sectores, dependían del Comando de la Quinta División en Iquitos, y podían ser abastecidas por vía fluvial de manera más o menos frecuente. La capital de Loreto estaba además conectada a Lima con una línea aérea regular desde finales de la década de 1920, que iniciaba en Chanchamayo (Patiño Ponce 2014), y la carretera Lima-Pucallpa, conectando la capital peruana a Iquitos por el 
río Ucayali, estaba casi terminada a principios de los años 1940. Las guarniciones ecuatorianas, ubicadas en los afluentes septentrionales del Marañón y del Amazonas, eran mucho más difíciles de abastecer ya que había que emprender el viaje por tierra, trochas o caminos difíciles, y parte importante del material llevado desaparecía en la selva cuando los cargadores indígenas (jibaros en general) huían con la mercancía. A pesar de numerosos proyectos nacionales, solo algunos caminos de importancia local habían sido concluidos (Esvertit Cobes 1995). Por lo tanto, las guarniciones ecuatorianas dependían, en algunos casos, del comercio con Iquitos y las guarniciones peruanas para sobrevivir.

Aisladas o no, las guarniciones de frontera peruanas y ecuatorianas no gozaban del confort moderno, tal como lo escribió el peruano Víctor Proaño en 1938 sobre la guarnición peruana de Barranca en el Marañón:

"Apena ver la pobreza de puestos militares de avanzada como éste, sin obras de defensa ocultas por camouflages, -según parece aconsejar la técnica militar modernani ostensibles; formados por simples chozas; sin instalación eléctrica; y desprovistos de todo confort. No se ve por ningún lado-aparte del escudo nacional sujeto a una triste casa pajiza y a oficiales y soldados de uniforme- nada que nos indique que estamos en un establecimiento guerrero, que debe ser siempre gallardo y simbólico. Parece de urgencia la construcción de cuarteles modernos, de arquitectura adecuada a la región y al clima, y con material noble y resistente" ${ }^{\prime \prime 3}$.

En estas guarniciones lejanas vivían, a veces por varios años, jóvenes soldados y oficiales al mando, desarrollando un estilo de vida peculiar. En el Perú, los oficiales, militares de profesión, podían ser de otras regiones, pero la mayoría de soldados venían del Nororiente y regiones cercanas, merced al servicio militar obligatorio. En cambio, las tropas ecuatorianas eran reclutadas en la sierra y la costa del país y conocían muy poco la vida y la geografía de la selva. Además, la oficialidad, tanto ecuatoriana como peruana, percibía su nominación en estas remotas tierras como un castigo, adonde se enviaba soldados "dominados por vicios" y "en lo que a Jefes de Unidad se refiere, un lugar de expiación de faltas políticas, disciplinarias, o de entrenamiento de recién reincorporados" ${ }^{14}$. Los hombres eran jóvenes: alrededor de 20 años para los soldados, no más de 30 para los oficiales de bajo rango.

Las condiciones sanitarias eran pésimas. Aunque los oficiales intentaban ubicar las guarniciones en los lugares más sanos posibles, las necesidades estratégicas conducían a instalar puestos militares en lugares propicios a las enfermedades, Histórico de Límites, Lima, LEK-20-7, legajo 176. Parece que este peruano era familiar de un general ecuatoriano quien había sido desterrado al oriente ecuatoriano antes de terminar su vida en Lima.

14 "Copia del informe que presentó el Comandante A. Witt al IV Departamento "Oriente" el 12 de enero de 1940, y ampliado a pedido del señor Ministro de Defensa, en febrero 7 del mismo año", Archivo Histórico del Ministerio de Relaciones Exteriores, Quito, T.5.3.1.1. 
además de que la falta de medicinas y de material adecuado empeoraba la situación sanitaria. Los soldados padecían de "paludismo, disentería, enfermedades intestinales, infecciones de la piel por lastimaduras, picaduras de insectos, escavies, abenitis inguinual, consecuencia de la infección de la piel" según el cirujano ecuatoriano de Méndez ${ }^{15}$, quien añadía que la disentería llevaba a enfermedades de encías y a operaciones dentales incómodas debido a la falta de material indicado. Cabe mencionar, sin embargo, que la presencia de médicos militares y de medicina para los soldados pudo ser aprovechada por las poblaciones locales, tal como lo indica el mismo informe: "el servicio médico y la botica [de Méndez] se ha extendido a los colonos que prestan servicios a la guarnición y al jíbaro que exige para él y su familia medicinas" ${ }^{\prime \prime}$.

Los soldados de estas guarniciones lejanas estaban además "abandonados a su propia suerte y por un tiempo indefinido" precisaba un informe ecuatoriano ${ }^{17}$. Este aislamiento debía llevar sin duda a un aburrimiento sistemático y a tratar de romperlo con las pocas diversiones que existían, el alcohol y los juegos de dinero, que se desarrollaban en los casinos militares que encontramos hasta en las guarniciones de Rocafuerte-Pantoja. El consumo de alcohol, si bien debía ser compartido por ecuatorianos y peruanos, parece haber sido un problema más grande del lado ecuatoriano. El teniente ecuatoriano Bustamante advertía que "el aguardiente se consume en Méndez [sede de una de las dos regiones militares del oriente ecuatoriano], el sábado y domingo, en cantidades ingentes, basta decir que en Méndez, hay 30 casas y 22 cantinas, es decir que solo no hay cantinas, en el cuartel, misiones, escuela y en tres casas particulares"18. El consumo de alcohol podía conducir a graves problemas de gestión de la tropa, y hasta a incidentes internacionales, como lo parece decir este informe peruano sobre la conducta de la tropa ecuatoriana de Rocafuerte en periodo de fiestas patrias:

“Originando sostenidas libaciones que se prolongan por 8 y hasta 15 días, prácticamente, hasta que se acaben los licores en venta, en cuyo tiempo desaparecen toda garantía de orden, subordinación y disciplina, pues se confunden por igual civiles, tropa, oficiales y jefes, abundando las arengas, discursos, verborrea desbordada que estimula apetitos contenidos en espíritus ya excitados por el alcohol"19.

El aburrimiento era combatido con otro método que fue conocido en las décadas siguientes por la novela de Vargas Llosa, Pantaleón y las Visitadoras, sobre la organización a gran escala de un sistema de prostitución para los soldados de la

15 "Informe sobre el Batallón oriental n 15 “Ecuador" presentado por el señor Mayor Marco A. Bustamante, Segundo Comandante", 28 de Enero de 1942, Archivo Histórico-Militar, Escuela Superior Militar "Eloy Alfaro", Quito.

$16 \quad$ Ibid.

$17 \quad$ Ibid.

$18 \quad$ Ibid.

19 Antonio Santisteban al Ministro de Guerra, 8 de junio de 1938, Archivo Histórico de Límites, Lima, LEK-9-15, legajo 169. 
selva, destinado a disminuir las violaciones a las mujeres nativas y mestizas. Este asunto ya se planteaba en los años 1930, cuando existía un sistema de prostitución, tal como describe el propio Víctor Proaño, en la única referencia que hemos encontrado al respecto, sin lugar a dudas debido a la naturaleza del tema:

"Las guarniciones militares de Loreto plantean un problema que no puede dejar de ser considerado: el problema sexual. Abusos de esta indole cometidos en las mujeres de ciertas tribus, determinaron ya el completo exterminio de una guarnición. Refiriéndonos solamente a los jefes y oficiales, es indudable que, por ahora, constituye un verdadero sacrificio para sus familiares ir a residir a lugares tan desamparados. Así es cómo buena parte de los oficiales solteros, y hasta casados, reciben en indecoroso traspaso, al llegar a las guarniciones a donde son destacados, o llevan desde Iquitos, mujeres mestizas o indígenas que han adoptado ese sistema de vida, acompañando por largas temporadas a los militares en esos puntos extremos, y volviendo a esta ciudad con ellos en espera de otros que les propongan igual contrato, cuando, como se ha visto, no fueron dejadas por los oficiales salientes a los entrantes. Dichas mujeres, cuando están en Iquitos, se dedican a la prostitución, abierta o embozada, y cuando vuelven a las guarniciones transmiten sus males venéreos a hombres que precisan de salud perfecta, más imperiosamente quizá que los que habitan en las ciudades. Frecuentemente, ese tráfico inmoral trae como tristísima consecuencia, el nacimiento de hijos, tarados muchas veces, abandonados casi siempre por sus padres, y que constituyen seria incógnita para la sociedad y para el Estado. Tales consecuencias se producen, agrandadas tal vez, en el elemento de tropa. Hay, con todo, abnegadas señoras que siguen a sus maridos y que, muy a pesar, tienen en cierto modo que convivir con tales mujerzuelas" ${ }^{\prime 2}$.

Asimismo, la presencia de las prostitutas, al costado de las esposas, conformaba una sociedad local muy peculiar que llevaba a un mestizaje local problemático para el Estado. La militarización tuvo un impacto demográfico y los soldados estaban en constante contacto con civiles de todo tipo: familias de militares, comerciantes en las grandes guarniciones, buscadores de oro, antiguos caucheros, misioneros, etc. Una situación que era agudizada en la población militar más grande del Oriente: Rocafuerte-Pantoja.

\section{Rocafuerte-Pantoja: una ciudad fronteriza militarizada}

Por su tamaño e importancia estratégica, las dos guarniciones de Rocafuerte (ecuatoriana) y Cabo Pantoja (peruana) merecen un párrafo aparte. Desde la primera década del siglo XX y los enfrentamientos de Angoteros y Torres Causana, estaban ubicadas en la margen norte del rio Napo, a la altura de la boca del río Aguarico, y separadas por un simple "puente internacional" donde se intercambiaban notas y prisioneros cuando aparecía el caso. Cada guarnición contaba con aproximadamente 
100 efectivos, dependiendo de las épocas. También estaban presentes las fuerzas fluviales peruanas. Las instalaciones militares, sin embargo, estaban separadas por poblaciones civiles de cada parte del puente, en la parte peruana por el pueblo de Bohemia, además de la población civil ubicada en el pueblito no tan lejos de Santa Rosa, conformada por comerciantes y/o familiares de los soldados. La confusión crecía con el hecho de que del lado ecuatoriano vivían peruanos y hasta colombianos, y que del lado peruano vivían por lo menos 9 ecuatorianos y que de ellos 4 habían nacido en la parte ecuatoriana ${ }^{21}$. En total, militares y civiles debieron sumar, dependiendo de las épocas, de 500 a 2000 personas, conformando una pequeña ciudad en medio de la nada, con sus escuelas, comerciantes, relaciones familiares e incidentes internacionales. La frontera internacional estaba lejos de ser un límite cerrado. Los intercambios ocurrían tanto entre militares de los dos países que se conocían y se encontraban en los casinos militares hasta el toque de queda, como entre militares y civiles para fines de comercio, como lo notaba este comentario sobre la parte peruana:

"Las reses que se consumen en la guarnición proceden de la población ecuatoriana de Arcadia, porque las del lugar no alcanzan para abastecer el consumo / existen dos tambos o tienduchas, en los que se explota a los soldados moradores, cobrándoseles los artículos con un $50 \% \mathrm{~m} / \mathrm{m}$ de recargo. Los cigarrillos y fósforos nacionales tienen poca salida por resultar más caros que los similares ecuatorianos, que se adquieren de contrabando en la guarnición ecuatoriana"22.

A medida que la presencia militar se reforzaba en la región, las tensiones se agudizaron en este pueblo frontera, hasta casi llevar a la guerra en 1938. La nueva guarnición peruana de El Infante, en Lagarto Cocha, afluente del Napo, debía ser abastecida por barcos que pasaban frente a Rocafuerte. Temiendo una nueva expansión peruana en la región y no queriendo crear una navegación libre por el Napo, el comandante ecuatoriano de Rocafuerte, Mayor Abelardo Aguirre, prohibió el paso de los barcos peruanos. Además, debido al incremento del valor del sol peruano, los comerciantes de Rocafuerte y de la región del Napo preferían vender a los peruanos, sobre todo el ganado. La guarnición ecuatoriana carecía de productos básicos producidos en haciendas ecuatorianas. Para impedir este efecto, Aguirre, quien además había sido denunciado varias veces por las autoridades peruanas por ser un extremista patriotero, tomó medidas para dar prioridad a su guarnición en el comercio, y estableció medidas más rígidas de vida de la guarnición. Todo esto creó un ambiente de tensión entre las dos guarniciones cuando en junio, soldados ecuatorianos y peruanos se enfrentaron justo en frente de las guarniciones, del

21 Ministerio de Relaciones Exteriores, "Relación parcial de personas nacidas en la zona ocupada por el Ecuador, quienes actualmente residen en las retaguardias de las guarniciones peruanas, con indicación de los lugares de residencia, procedencia, nombre, edad y posición en el hogar", 17 de marzo de 1941, Archivo Histórico de Límites, Lima, LEK-20-33, legajo 177

22 Ricardo E.Llona, Coronel Presidente de la Comisión, "Estudio sobre el río Napo", 29 de agosto de 1934, Archivo Histórico de Límites, Lima, LEK-20-40, legajo 177. 
otro lado del Napo, donde existía una divergencia de interpretación de la frontera internacional con el Statu quo de 1936. Un soldado ecuatoriano falleció y 5 fueron hechos prisioneros ${ }^{23}$.

Su interrogatorio indicaba que eran jóvenes de 20 a 26 años, y que estaban todos borrachos. Los periódicos ecuatorianos, al parecer informados por el comandante Aguirre a través de su radio, una de las pocas del lado ecuatoriano, denunciaron un ataque peruano de gran amplitud, incluso con cañoneras. Todos los periódicos del continente, desde Buenos Aires hasta Nueva York, comentaron los hechos, que caían mal en el contexto de negociaciones en Washington entre Perú y Ecuador desde hacía dos años, y que fueron de hecho abandonadas ese mismo año. Finalmente, las dos cancillerías tranquilizaron a sus soldados y los jefes de las dos guarniciones fueron removidos para impedir este tipo de escalada, pero la tensión persistió, y tres meses después el comandante de la V División Peruana pedía a su Ministro abandonar el Statu Quo y avanzar lo más posible a lo largo de los ríos ${ }^{24}$.

\section{Una bomba diplomática}

Este incidente es típico de los numerosos incidentes de frontera en la región que se deben, para empezar, por la situación en la cual se encontraba la tropa: hombres jóvenes, aburridos y a veces muy lejos de sus casas, con pocos contactos con el resto del país menos con la sociedad local. Las únicas distracciones se encontraban en las pocas mujeres, el alcohol y el juego, lo que podía llevar siempre a malentendidos. Era una especie de "far west". Y, para los soldados rasos, debía ser difícil percibir una estrategia a gran escala del Estado Mayor, por si acaso existiera. En este contexto, la falta de disciplina, el patriotismo caricaturesco y los periódicos nacionales, anunciando invasiones imaginarias, echaban aceite al fuego. Además, en esta pequeña sociedad fronteriza, todo el mundo era sospechoso.

El colono, de dudosa lealtad nacional y moralidad, el indígena transfronterizo "indomable" y peligroso, el viajero, aventurero o científico de paso o el misionero extranjero, todos podían estar (y de hecho algunos estaban) recopilando datos sobre las tropas del enemigo: ubicación de las guarniciones, número de tropas, trochas y vías de acceso. Las sospechas eran reforzadas por la práctica de los dos bandos de mandar expediciones de reconocimiento vistiendo a los soldados de civiles para fingir ser simples colonos, lo que alimentaba la sospecha hacia cualquiera. Esta paranoia alimentaba buena parte de los informes de los dos lados que intentaban con mucha exageración describir lo que hacían las guarniciones enemigas, donde

Mayor Abelardo B. Aguirre S., “Parte que el Comandante saliente del Batallón Oriente ${ }^{\circ} 14$ presenta a la consideración del Señor Coronel Jefe del IV departamento del Ministerio de Defensa Nacional, sobre sus actividades desarrolladas durante los meses de enero a julio de 1938, y referentes al aspecto internacional", 22 de agosto de 1938, Archivo Histórico del Ministerio de Relaciones Exteriores, Quito, T.5.3.1.4. Histórico de Límites, LEK-7-17, “Límites con Ecuador, 1938-1940”. 
estaban y hasta donde se extendía la influencia del país vecino, lo que llevaba a expediciones de reconocimiento, llevando a nuevos incidentes de frontera y a una tensión aún mayor.

A este espíritu de desconfianza se agregaba una verdadera incertidumbre geográfica. Hay que subrayar la falta de una definición clara de la frontera internacional que daba lugar a todas las interpretaciones, y un desconocimiento problemático de la geografía regional, hasta en las más altas esferas del Estado.

En 1936, las más altas autoridades geográficas ecuatorianas admitían su incompetencia ya que "no ha sido posible hasta hoy - y de esto hay que lamentarse - conocer a ciencia cierta qué es lo que realmente tenemos en la zona Oriental (...) El señor Geógrafo de la Comisión Técnica, en la sesión de ayer, expresó terminantemente que no podía precisar ni la realidad de las posiciones ecuatorianas, ni el alcance efectivo de la ocupación peruana en el Oriente" ${ }^{25}$. Del lado peruano, la situación era igual de difícil, puesto que en el conflicto de Leticia «no había una sola carta geográfica del Oriente a la que pudiera calificarse siquiera de regular» (Romero 1934: 183).

Este desconocimiento de la geografía era un problema para las negociaciones diplomáticas que se habían iniciado en Washington en 1936, puesto que, para llegar a un acuerdo sobre la frontera, había que conocer precisamente el espacio. Los diplomáticos pedían informaciones proporcionadas por militares y a veces por misioneros. Para conseguir estos datos, los destacamentos armaban viajes de reconocimiento durante los cuales encontraban a menudo a soldados de la República vecina. La línea del Statu Quo no permitía establecer con claridad la frontera provisional ya que si este documento afirmaba que las tropas debían permanecer donde estaban en el momento de la firma, no precisaba esta ubicación. Por lo tanto, las tropas de los dos países podrían iniciar un incidente de frontera, que amenazaba arruinar las negociaciones de Washington y desatar una guerra abierta. Paranoia, aburrimiento, incertidumbres geográficas y diplomáticas se acumularon durante esa década para producir una quincena de incidentes de este tipo, cuyos ejemplos del Santiago en 1936 y del Napo en 1938 que hemos detallado son los más destacados.

\section{Conclusión}

La militarización de los orientes peruanos y ecuatorianos fue un proceso que se autoalimentó. Las acusaciones y exageraciones de las fuerzas del enemigo justificaban el incremento de sus propias fuerzas, o por lo menos el pedido que este se incrementase. En efecto, queda claro que los peruanos, con más recursos y

25 "Informe Reservado presentado por el Ministro de Defensa Nacional, Coronel Guillermo Freile, al Gobierno y Junta Consultativa, haciendo historia de las incursiones peruanas en el Oriente Ecuatoriano desde el año 1935", 3 de marzo de 1938, Archivo Histórico del Ministerio de Relaciones Exteriores, Quito, T.5.3.1.4. 
menos inestabilidad política que sus vecinos, lograron establecer una frontera sólida después del choque de 1932, sin que significara la puesta en marcha de una invasión generalizada a Ecuador. Los ecuatorianos carecían de recursos, pero desencadenaron una actividad administrativa y local que, de cierta forma, alimentaba los esfuerzos peruanos.

A pesar que estas militarizaciones eran consecuencia de iniciativas locales, el desequilibrio de las fuerzas armadas a finales de los años 1930 traducía una diferencia de estrategia global hacia los orientes, resumida en el comentario de un comandante peruano sobre un misionero salesiano ecuatoriano en 1932 de que "antes de que él funde la capilla, pondré guarnición, para sacarlo a palos cuando llegue este Fraile" 26 . En el Perú, si bien las órdenes religiosas desempeñaron un papel primordial en la nacionalización de la Amazonía hasta los años 1930 (García Jordán 1995), parece que en esa década fueron igualadas por las fuerzas militares como la institución encargada de integrar aquellas tierras y poblaciones a la nación aunque, como lo hemos visto en el caso de los indígenas, el ejército gozó en su tarea de la "herencia" de la labor misional, la cual había abierto caminos, fundado pueblos y evangelizado algunos indígenas. En cambio, en Ecuador el desempeño militar de los años 1930 no puso en tela de juicio el pacto del Estado con las órdenes religiosas para colonizar el oriente, por lo menos hasta la guerra de 1941. Es precisamente esta guerra que provocó una "conmoción [que] se expresó en la creciente militarización de las zonas de frontera, instalándose bases en diversas zonas del Oriente» (Esvertit Cobes 2012: 476).

Esta militarización inconclusa tuvo sus frutos en la segunda mitad del siglo XX. Pero cabe subrayar la originalidad de esta década de transición de los orientes peruanos y ecuatorianos que, al lado de las misiones, las autoridades civiles, los ingenieros, la inmigración extranjera o nacional, los exploradores y científicos, colocó a los soldados y oficiales en primera plana como agentes de integración de la Amazonía a los Estados modernos. 12 de Mayo de 1933, Archivo Histórico del Ministerio de Relaciones Exteriores, Quito, T.5.1.20. 


\section{Bibliografía}

Calderón, William y Juan Mendoza

2016 Gasto militar en el Perú. Lima: Universidad del Pacífico.

Camacho Arango, Carlos

2016 El conflicto de Leticia (1932-1933) y los ejércitos de Perú y Colombia. Bogotá: Universidad Externado de Colombia.

Del Mar Alcázar, Gerardo

1980 Conflicto militar del Perú con el Ecuador, 1941, en el teatro de operaciones del nor-oriente. Sin editor. Lima.

Esvertit Cobes, Natalia

1995 «Caminos al Oriente. Estado e intereses regionales en los proyectos de vías de comunicación con la Amazonía ecuatoriana, 1890-1930». En: García Jordán, P. (ed.), La construcción de la Amazonía andina (siglos XIX-XX). Quito: Abya-Yala, pp.287-356

Esvertit Cobes, Natalia

2012 «Los salesianos en el Vicariato Apostólico de Méndez y Gualaquiza: configuración territorial, colonización y nacionalización del Suroriente ecuatoriano, siglos XIX y XX». En: Vásquez S., L., Torres D., V.H., Juncosa, J.E., Regalado, J.F. y Garzón, B. (eds.), La presencia salesiana en Ecuador: perspectivas históricas y sociales. Quito: Abya Yala/Universidad Politécnica Salesiana. pp.477-518.

García Jordán, Pilar

1995 «Las misiones católicas en la Amazonía peruana: ocupación del territorio y control indígena (1821-1930)». En: García Jordán, P. (ed.), La construcción de la Amazonía andina (siglos XIX-XX). Quito: Abya-Yala. pp.7-106.

Guallart, José María

1981 Fronteras vivas: poblaciones indígenas en la cordillera del Cóndor. Lima: Centro Amazónico de Antropología y Aplicación Práctica.

Guallart, José María

1990 Entre pongo y cordillera: historia de la etnía aguaruna-huambisa. Lima: Centro Amazónico de Antropología y Aplicación Práctica.

Lloret Orellana, Patricio

2013 «El ejército en los años 30». En: Boletín de la Academia Nacional de Historia Militar (5): 187-242. 
Macías Núñez, Édison

2007 El ejército ecuatoriano en la revolución alfarista, su desarrollo y posterior decadencia. En: Historia General Del Ejército. Vol. 4. Quito: Centro de Estudios Históricos de Ejército.

Macías Núñez, Édison

2012 El ejército ecuatoriano en la campaña internacional de 1941 y en la post guerra. En: Historia General Del Ejército. Vol. 5. Centro de Estudios Históricos del Ejército.

Masterson, Daniel M.

2001 Fuerza armada y sociedad en el Perú moderno: un estudio sobre relaciones civiles militares, 1930-2000. Lima: Instituto de Estudios Políticos y Estratégicos.

Paredes, L.H.

1934 «Ensayo de Proyecto de Reglamento de Guarniciones de Fronteras para la Región de Selva». En: Revista militar del Perú, Año XXXI (6): 743-754.

Patiño Ponce, J.C.

2014 «La conquista aérea de la Selva». En: Casaretto Alvarado, F. (Ed.), Marina de Guerra Del Perú. La Odisea Amazónica. 1864-2014. Iquitos: Comandancia General de Operaciones de La Amazonía y Quinta Zona Naval. pp.155167.

Rodríguez Asti, John

2008 Las operaciones navales durante el conflicto con el Ecuador, 1941: apuntes para su historia. Lima: Marina de Guerra del Perú.

Romero, F.

$1934 \quad$ Notas para una historia de la Marina fluvial de Guerra.

Romero, F.

1935 Las fuerzas de la Marina en el Nor-Oriente y la guerra fluvial. Lima: Secreto.

Torres V., O.N.

1935 Las operaciones militares en terreno selvático. Lima: Imprenta y Librería del Gabinete Militar.

Villar Gálvez, Raymundo

1999 «La Marina de Guerra del Perú en la región amazónica». En: Revista de Marina (edición especial «Amazonía»): 99-138.

Walker, Charles

1987 «El uso oficial de la selva en el Perú republicano». En: Amazonía peruana (4): 61-89. 
Zanabria Zamudio, Rómulo

Luchas y victorias por la definición de una frontera. Lima: Editorial Jurídica, 1969.

Zárate Botía, C.G.

2012 «Pueblos indígenas y expediciones de límites en la Amazonía, siglos XVIII-XX». En: Rubio Correa F., Chaumeil J.-P., Camacho Pineda, R. (Eds.), El Aliento de La Memoria: Antropología e Historia En La Amazonia Andina, Bogotá: Universidad Nacional de Colombia. Facultad de Ciencias Humanas. Departamento de Antropología. pp.261-283. 


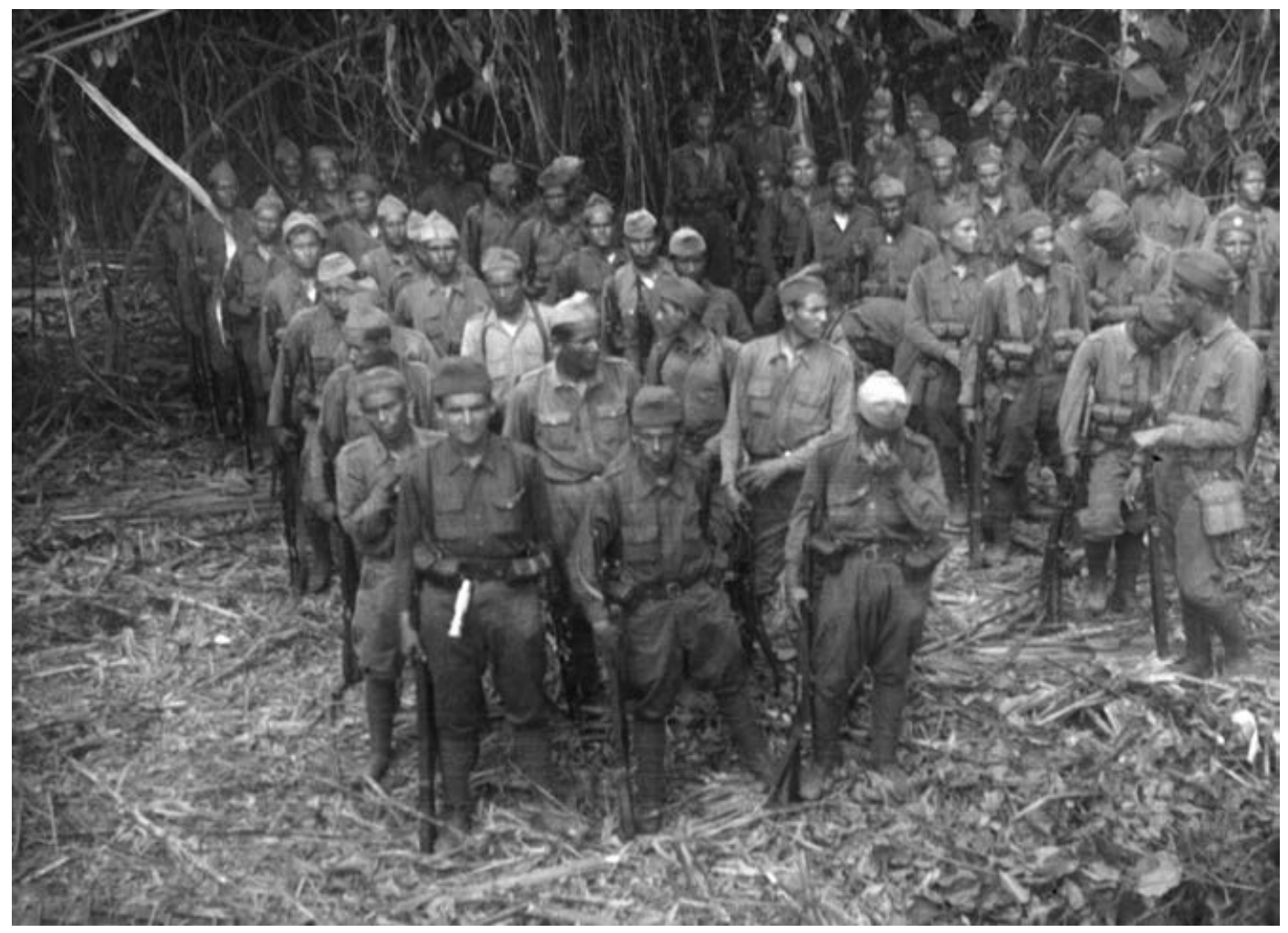

Tropas peruanas en la frontera con el Ecuador inicios década 1940 Fotógrafo anónimo. Archivo Histórico de Marina 